\title{
Microstructure and Mechanical Properties of Al-SiC Nanocomposites Synthesized by Surface-Modified Aluminium Powder
}

\author{
Xiang Zeng ${ }^{1,2}$, Wei Liu ${ }^{2}$, Ben $\mathrm{Xu}^{2}$, Guogang Shu ${ }^{3}$ and Qiulin Li ${ }^{1}$ * \\ 1 Graduate School at Shenzhen, Tsinghua University, Shenzhen 518055, China; \\ zeng-x15@mails.tsinghua.edu.cn \\ 2 School of Materials Science and Engineering, Tsinghua University, Beijing 100084, China; \\ liuw@mail.tsinghua.edu.cn (W.L.); xuben@mail.tsinghua.edu.cn (B.X.) \\ 3 State Key Laboratory of Nuclear Power Engineering Co. Ltd., Shenzhen 518172, China; \\ shuguogang@cgnpc.com.cn \\ * Correspondence: liq1@sz.tsinghua.edu.cn; Tel.: +86-0755-26036032
}

Received: 5 March 2018; Accepted: 3 April 2018; Published: 9 April 2018

\begin{abstract}
Ceramic nanoparticle-reinforced aluminium metal matrix composites (AMMCs) have superior mechanical properties compared with matrix alloys, exhibiting great potential in structural applications in industries such as the aerospace and automotive sectors. This research proposes a new method for distributing $\mathrm{SiC}$ nanoparticles in an aluminium matrix alloy by powder metallurgy. The mixing of aluminium powder and $\mathrm{SiC}$ nanoparticles was processed by a two-step procedure, which included ultrasound-assisted stirring and planetary agitation. After that, the mixing powder was subjected to compaction, sintering and extrusion. A blank sample and three composite sheets containing 1, 2 and $3 \mathrm{wt} \% \mathrm{SiC}$ nanoparticles were prepared and the mechanical properties were investigated by micro-hardness and tensile tests. A scanning electron microscope (SEM) and electron back-scattered diffraction (EBSD) were used for microstructural analysis of the composite. Experimental results revealed that by adding 1,2,3 wt \% SiC nanoparticles, hardness was increased by $26 \%, 34.5 \%, 40.0 \%$ and tensile strength was increased by $22.3 \%, 28.6 \%$ and $29.3 \%$, respectively. The grain size of the aluminium matrix decreased with the addition of $\mathrm{SiC}$ nanoparticles. Moreover, a decrease of elongation was observed with the increasing weight fraction of $\mathrm{SiC}$.
\end{abstract}

Keywords: metal matrix nanocomposite; powder metallurgy; $\mathrm{SiC}$; mechanical properties

\section{Introduction}

With advances in the field of material science, demand for lighter weight and higher strength materials is increasing. Metal matrix nanocomposites reinforced with ceramic particles are very promising materials for aerospace, automobile and defense applications due to the excellent combination of properties [1-7]. Compared to micro-sized ceramic particles, the nanoparticles exhibit a more efficient ability as reinforcement for metal matrix composites [8]. Ma et al. reported that aluminium composite reinforced by only $1 \mathrm{vol} \% \mathrm{Si}_{3} \mathrm{~N}_{4}\left(\mathrm{D}_{50}\right.$ is about $\left.10 \mathrm{~nm}\right)$ had nearly the same tensile strength and even much higher yield strength compared to $15 \mathrm{vol} \% \mathrm{SiC}\left(\mathrm{D}_{50}\right.$ of about $3.5 \mu \mathrm{m}) / \mathrm{Al}$ composite [9]. Silicon carbide ( $\mathrm{SiC})$ and aluminium oxide $\left(\mathrm{Al}_{2} \mathrm{O}_{3}\right)$ nanoparticle-reinforced aluminium metal matrix composites have drawn lots of attention for their economic advantages and better performance. Many methods can be used for fabrication of $\mathrm{Al}$ matrix nanocomposites such as infiltration [10], squeeze casting [11], mechanical alloying [12], powder metallurgy [13], ball milling [14] and stir casting [15]. Among these methods, powder metallurgy and stir casting are the most used at present for their economic advantages and also have the most potential for mass production. However, 
it is known that it is extremely difficult to obtain uniform dispersion of the nano-sized ceramic particles in the liquid metals due to the poor wettability between them and the metal matrix [16]. Powder metallurgy avoids the wettability problem, but the distribution of nanoparticles in the matrix powder is also challenging. At present, the distribution of nanoparticles is usually done by ball milling or mechanical alloying, which is complicated, expensive and energy-consuming [17]. It also inevitably introduces impurities into the composite and the cold welding during the mixing process will also lead to the oxidation of the powder.

Herein, we propose a new method for mixing powder. The new technique avoids the cold welding during the ball milling or mechanical alloying and thus minimizes the oxidation of aluminium powder. It is also time-saving and energy-efficient compared to ball milling [18-20]. The effect of SiC nanoparticles on the microstructure and mechanical properties of the as-prepared aluminum matrix composite was studied and the strengthening mechanism was also discussed.

\section{Materials and Methods}

The traditional powder metallurgy technique, which consists of mixing, compaction and sintering, was employed to manufacture the samples. The chemical composition of aluminium powder is given in Table 1. Aluminum powder particles (supplied by Beijing HuiSheng Advanced Materials Technology Co., Ltd., Beijing, China) and silicon carbide nanoparticles (supplied by Hefei Kaier Nanometer Energy Polytron Technologies Inc., Hefei, China) were used as the raw materials for the Al-SiC nanocomposite. A new method of mixing was used to distribute nanoparticles in the matrix powder. The schematic of the preparation process was pictured in Figure 1. First, 1, 2 and 3 wt \% silicon carbide nanoparticles were dispersed in $50 \mathrm{~mL}$ ethanol by ultrasound-assisted stirring. Then aluminum powder was added to the mixture. After that, the slurry was processed by a planetary mixer (ZYMC-700VS, ZYE, Shenzhen, China). The revolution speed was $2000 \mathrm{r} / \mathrm{min}$ and rotation speed was $800 \mathrm{r} / \mathrm{min}$. After mixing for $90 \mathrm{~s}$, the vacuum pump was turned on while the revolution and rotation were kept running to evaporate the ethanol for about $60 \mathrm{~s}$. Then, the mixture was subjected to a vacuum oven (Yiheng, Shanghai, China) for further drying. After that the powder mixture was pressed by cold isostatic pressing (CIP) at $400 \mathrm{MPa}$. The green compacts were about $100 \mathrm{~mm} \times \varnothing 105 \mathrm{~mm}$, and subjected to a vacuum sintering furnace (ACME, Changsha, China) at $600{ }^{\circ} \mathrm{C}$ for $12 \mathrm{~h}$ at $0.1 \mathrm{~Pa}$ vacuum. Finally, the sintered composite was machined to $90 \mathrm{~mm} \times \varnothing 90 \mathrm{~mm}$, preheated up to $500{ }^{\circ} \mathrm{C}$ and extruded with the extrusion ratio of 9:1. The final product was a plate with the width of $60 \mathrm{~mm}$, thickness of $12 \mathrm{~mm}$, and length of $800 \mathrm{~mm}$.

Table 1. The chemical composition of aluminium powder.

\begin{tabular}{cccccccccc}
\hline Elements & Al & $\mathbf{C}$ & Si & Mg & O & N & Fe & Cu & Others \\
\hline Content $(\%)$ & 99.93 & 0.003 & 0.002 & 0.002 & 0.05 & 0.001 & 0.001 & 0.001 & $\leq 0.01$ \\
\hline
\end{tabular}

The mechanical properties of the samples were obtained by tensile test and micro-hardness tests. Tensile specimens were machined into rectangular specimens along the extrusion axis direction according to ASTM E8M standards for subsize specimens. The dimension of the tensile specimen is shown as Figure 2. Tensile tests were carried out using a MTS Landmark testing system (MTS, Eden Prairie, MN, USA) with a strain rate of $10^{-3} \mathrm{~s}^{-1}$ and an average value was obtained from four tensile tests for each sample. The Vickers microhardness tests were carried out with a load of $500 \mathrm{~g}$ and dwelling time of $15 \mathrm{~s}$ on the metallographically polished samples based on the ASTM E92 standard. The average value of 10 measurements was reported for each sample.

A HITACHI SU8010 scanning electron microscope (Hitachi, Tokyo, Japan) was used for the microstructural observation of the synthesized nanocomposite. Samples were subjected to mechanical polishing before observing. Mechanical polishing was done by grinding through 180, 400, 600, 800, 1000 , 1200, 1500, 2000 grit alumina papers followed by polishing with 5, 2.5, $0.5 \mu$ m diamond paste and water. Then, the samples were etched by Keller's reagent. Specimens for electron back-scattered 
diffraction (EBSD) analyses (TESCAN MIRA 3 LMH; Oxford Instruments, Shanghai, China) were sectioned along the extrusion axis direction, followed by mechanical grinding and an ion beam cross section polisher (IB-09020CP, Joel, Tokyo, Japan), successively. Step size between points on the scan grid was set to $0.3 \mu \mathrm{m}$.

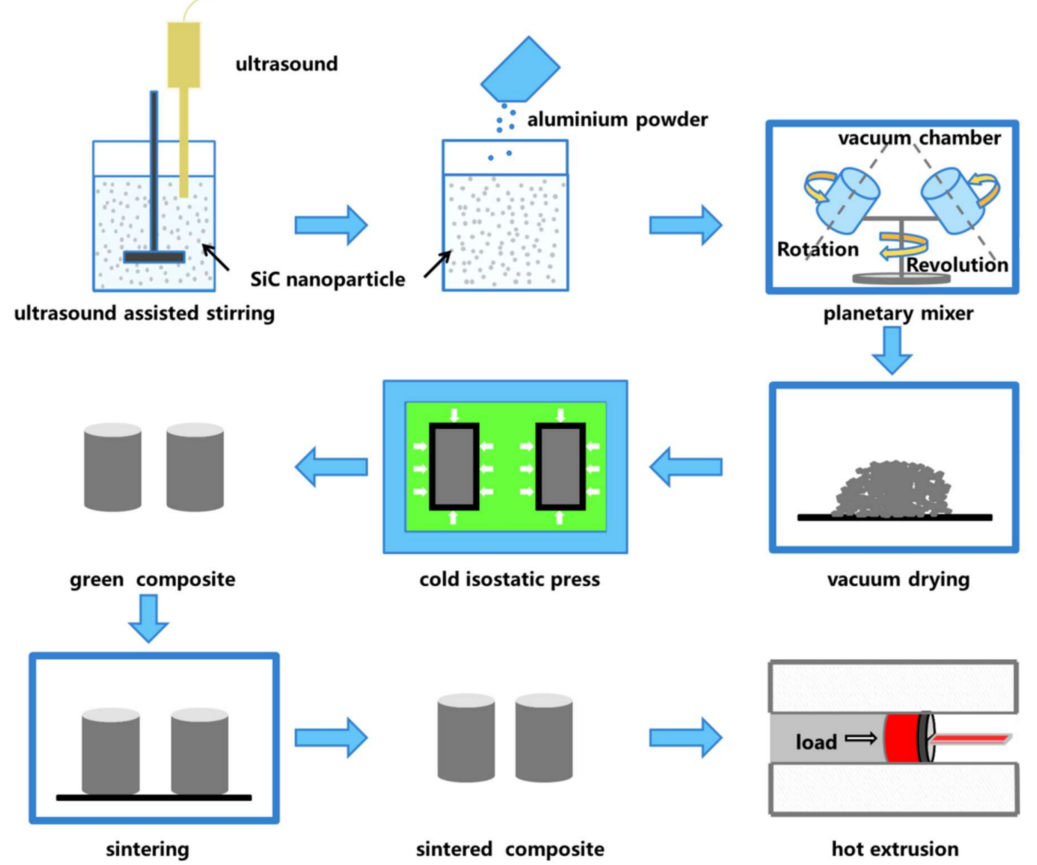

Figure 1. Schematic illustration of preparation process.

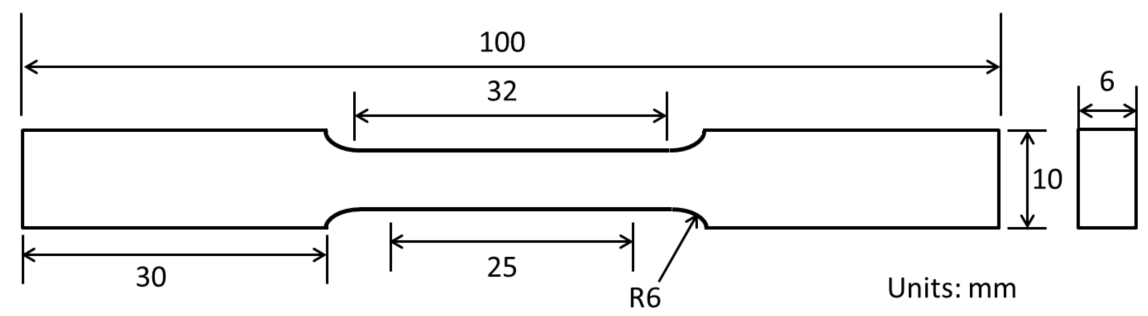

Figure 2. Dimension of tensile specimen.

\section{Results}

\subsection{Characterization of the As-Mixed Composite}

The effect of the mixing process on the distribution of the nanoparticles on the surface of the aluminium powder was studied using SEM. The morphology of the aluminum powder particles and silicon carbide ( $\mathrm{SiC}$ ) nanoparticles as-received is shown in Figure $3 \mathrm{a}, \mathrm{b}$. The inserts were the particle-size distribution of the aluminium and silicon carbide. Figure 4 shows the composite powder after the mixing process. A micrograph of composite containing $1 \mathrm{wt} \%$ of silicon carbide nanoparticles is shown in Figure $4 \mathrm{a}$, which shows that the $\mathrm{SiC}$ nanoparticles adhere to the aluminium particles with a relatively uniform distribution on the surface of the aluminium particles. Besides that, the shape of the aluminium particles did not change and remained near-spheroidal. However, as shown in Figure $4 \mathrm{~b}, \mathrm{c}$, it can be found that the shape of the aluminium particles has changed a little and some aluminium particles are agglomerated. This may be caused by the cold welding during the mixing process. 

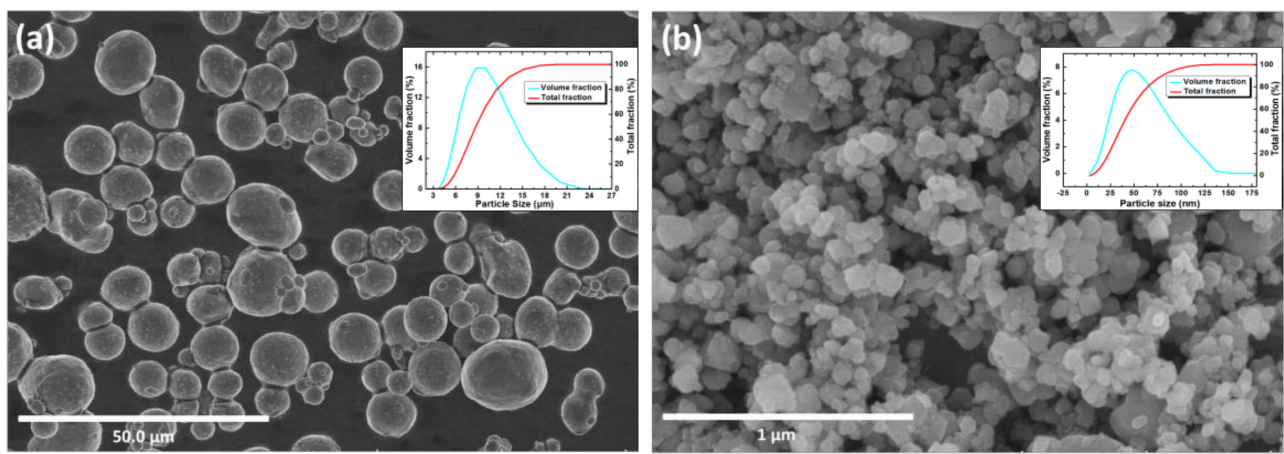

Figure 3. (a) As-received aluminium powder; (b) SiC nanoparticles.
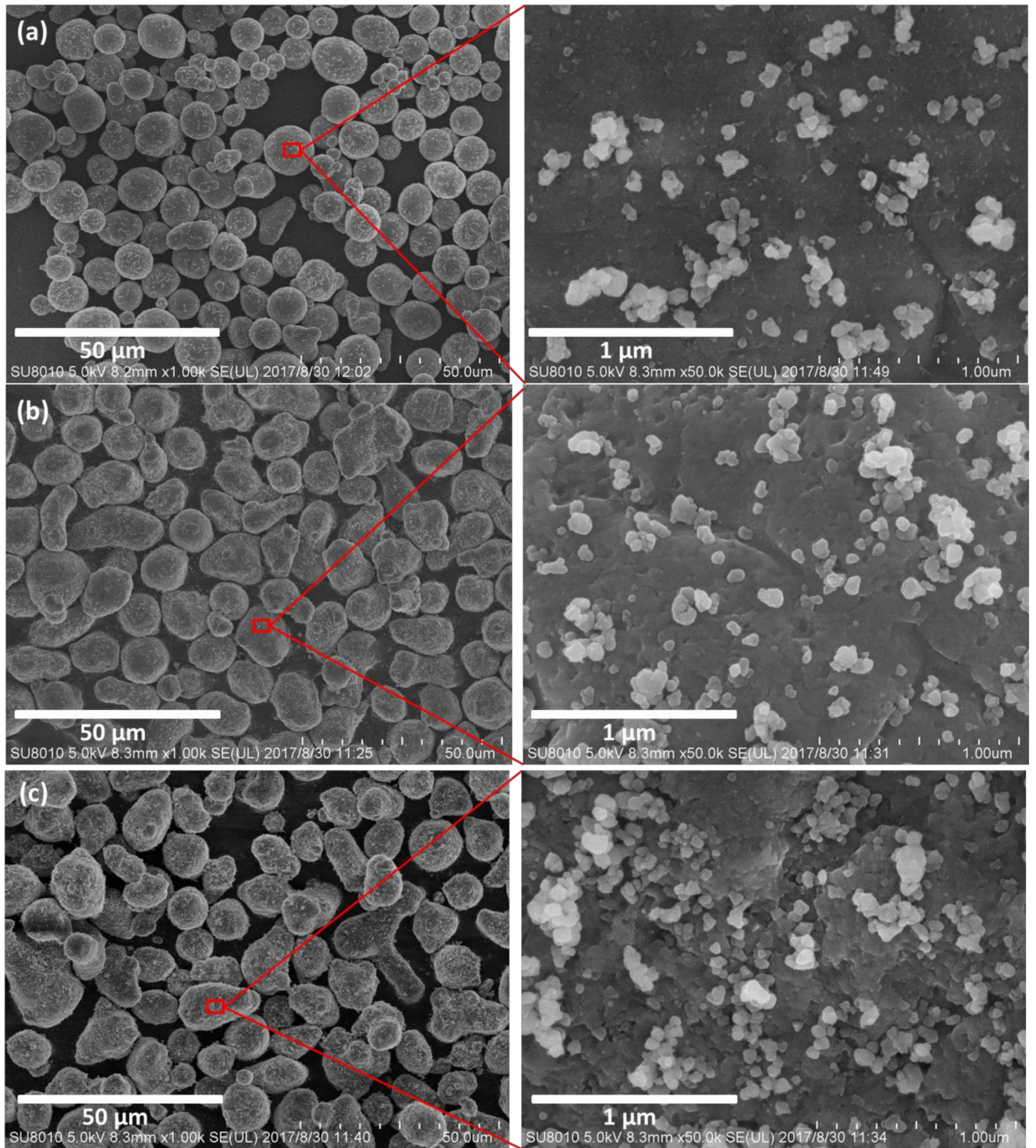

Figure 4. The aluminium powder after the mixing with $\mathrm{SiC}$ nanoparticles: (a) Al-1 wt \% SiC; (b) Al-2 wt \% SiC; (c) Al-3 wt \% SiC. 


\subsection{Microstructure}

Figure 5 illustrates the SEM micrographs of the monolithic and nanocomposite samples. As shown in the figure marked by red circles, the nanoparticles have been homogeneously dispersed in the aluminium matrix after extrusion. In the deformation of composites during the extrusion, the nanoparticles attached to the surface of aluminium particles were redistributed by the dynamic recrystallization of aluminium grain. The silicon carbide nanoparticles were dispersed and embedded into aluminium matrix after extrusion. Some agglomeration of several nanoparticles can still be found in Figure 5. That may be caused by the high specific surface area of the nanoparticles, which led to a tendency to cluster.

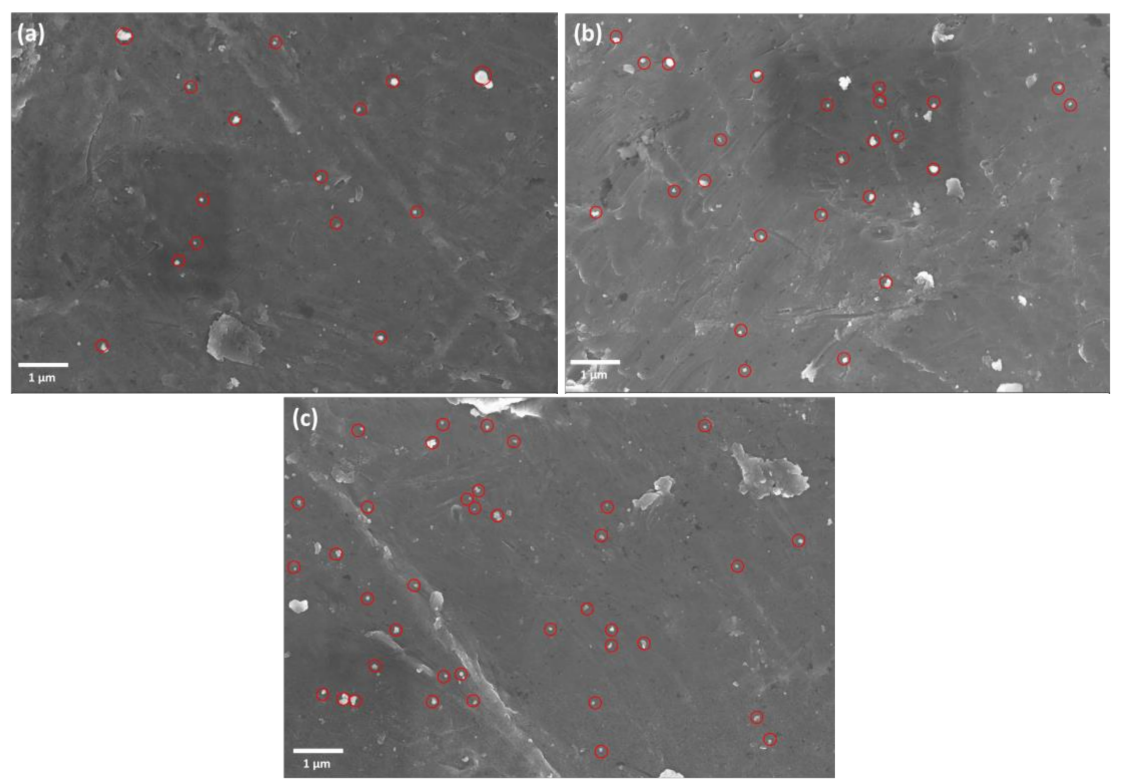

Figure 5. The scanning electron microscope (SEM) micrograph of extruded samples (a) Al-1wt \% SiC; (b) Al-2 wt \% SiC; (c) Al-3 wt \% SiC.

\subsection{Hardness}

The microhardness of the nanocomposites was measured 10 times for each sample and the average results are shown in Figure 6. As the blue column shows, with the addition of nanoparticles by $1 \mathrm{wt} \%, 2 \mathrm{wt} \%$ and $3 \mathrm{wt} \%$, the Vickers microhardness of the nanocomposite sample increased by about $26 \%, 34.5 \%, 40 \%$ compared to the pure aluminum sample. This significant increase in microhardness could be attributed to the presence of distributed hard ceramic nanoparticles in the metallic matrix. Silicon carbide has a higher hardness and modulus of elasticity than aluminium. Thus, it is reasonable to infer that the microhardness of the composite is higher than matrix alloy as long as the reinforcement phase is distributed uniformly in the matrix. In addition, the presence of ceramic nanoparticles prevented the movement of dislocations which limited the deformation of the nanocomposite. That should be the most important reason accounting for the increase in microhardness of the composite. 


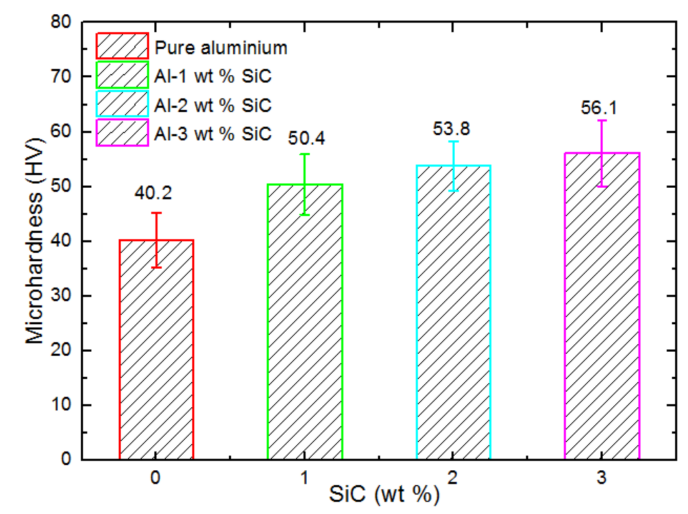

Figure 6. The microhardness of nanocomposite samples in different weight fractions of nano-SiC.

\subsection{Density Measurement}

Figure 7 compares the experimentally measured and theoretically calculated density for samples reinforced with different weight fractions of reinforcements. Theoretical density is calculated according to the rule of mixture as follows:

$$
\rho_{\text {composite }}=\rho_{\mathrm{Al}} \cdot \omega_{\mathrm{Al}}+\rho_{\mathrm{SiC}} \cdot \omega_{\mathrm{SiC}}
$$

where $\rho_{\text {composite, }} \rho_{\mathrm{Al}}$ and $\rho_{\mathrm{SiC}}$ refer to the density of composite, aluminium and silicon carbide, respectively; and $\omega_{\mathrm{Al}}$ and $\omega_{\mathrm{SiC}}$ are the volume fraction of aluminum and silicon carbide in nanocomposite. As seen from Figure 7, the density of the composites became bigger after extrusion. That means extrusion can decrease the porosity formed in the cold isostatic press. Besides that, it is evident that the density of the composites tends to become smaller as the content of nanoparticles becomes higher. It is reasonable that the nanoparticles attached to the surface of the aluminium particles prevent the integration of aluminum particles during sintering.

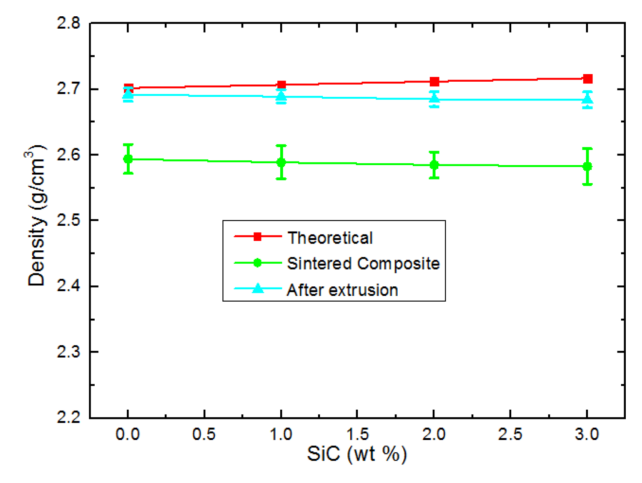

Figure 7. Comparison between experimental and theoretical density of nanocomposite samples at different weight fractions of nano-SiC.

\subsection{Tensile Properties}

Tensile tests were conducted on pure aluminum and Al-SiC nanocomposite samples. The engineering strees-strain curve is shown in Figure 8. The improvement in tensile strength is clearly observed for the composite compared to pure aluminum. The ultimate tensile strength was increased by $22.3 \%$, $28.6 \%$ and $29.3 \%$ with the addition of $1,2,3 \mathrm{wt} \% \mathrm{SiC}$ nanoparticles. However, a decrease in the elongation was also observed. The elongation drops from $13.5 \%$ to $4.7 \%$ when adding $3 \mathrm{wt} \% \mathrm{SiC}$ nanoparticles to pure aluminium. This may be caused by the increasing number of pores in the matrix alloy. We will discuss this later. 

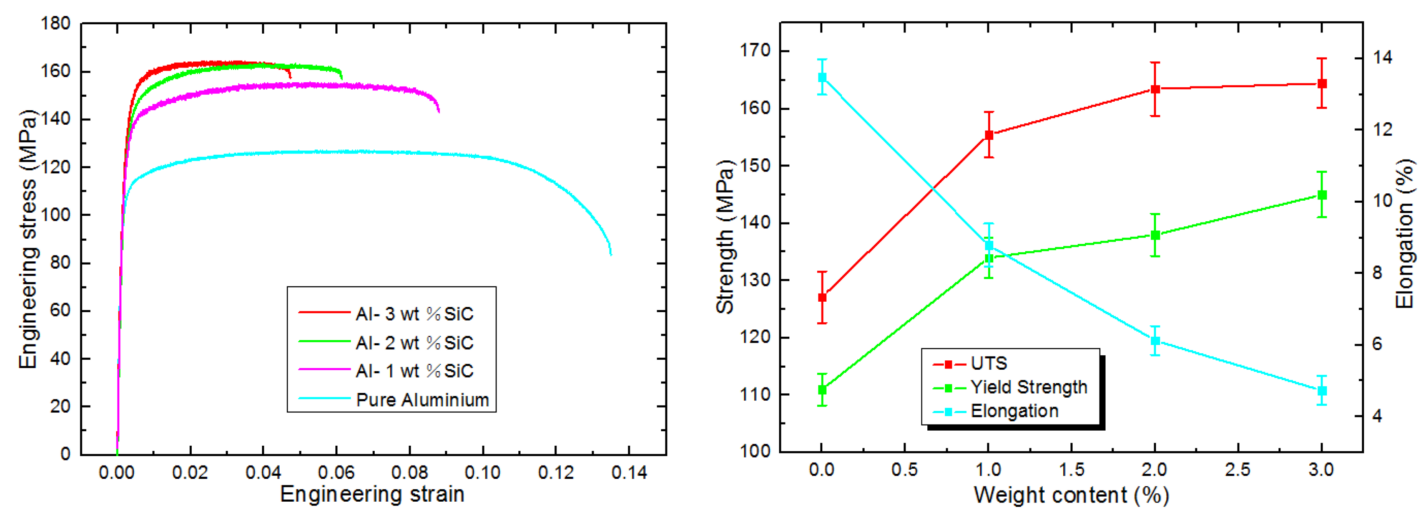

Figure 8. Tensile stress-strain curve of pure aluminum and Al-SiC nanocomposites at room temperature.

\section{Discussion}

Several mechanisms and theories have been proposed to elucidate the strengthening of metal matrix composites. We believe that the strength of composites is the result of several mechanisms acting together. These include Orowan strengthening, strengthening due to grain refinement, strengthening due to the formation of internal thermal stress resulting from different coefficient of thermal expansion (CTE) values between the matrix and the reinforcement particles, strengthening due to the effective load transfer between the matrix and the reinforcement, and hardening due to the strain misfit between the reinforcing particulates and the matrix. In this work, the strengthening of the composites may be attributed to three mechanisms principally: (i) Orowan strengthening; (ii) thermal expansion mismatch strengthening; and (iii) fine-grain strengthening. Clear discussion about these three principles is shown as follows.

Orowan strengthening is also known as dispersion hardening, which means that the strengthening is caused by dispersed second phase. In this work, Orowan strengthening is expected to be the main strengthening mechanism in the as-prepared nanocomposites. The Orowan strengthening mechanism is given by the Orowan-Ashby equation [21]:

$$
\sigma_{\text {Orowan }}=\frac{0.13 G b}{\lambda} \ln \frac{d}{2 b}
$$

where $G$ is the shear modulus of $\mathrm{Al} ; b$ is the Burgers vector of $\mathrm{Al} ; d$ is the average diameter of nanoparticles; and $\lambda$ is the interparticulate distance between the reinforcement particles, which is given by the following equation [22]:

$$
\lambda=d\left[\left(\frac{1}{2 f}\right)^{1 / 3}-1\right]
$$

where $f$ is the volume fraction of the reinforcement particles. As Equation (3) shows, increasing the amount of SiC from $1 \mathrm{wt} \%$ (0.85 vol \%) to $3 \mathrm{wt} \%$ (2.54 vol \%) leads to a decrease in the distance between the $\mathrm{SiC}$ nanoparticles, which results in the increase of $\sigma_{\text {Orowan. }}$. This is the reason for the enhanced strength of the nanocomposites. In terms of dislocation motion, the $\mathrm{SiC}$ nanoparticles prevent the movement of dislocations in the aluminium matrix, as shown in Equation (4):

$$
T_{0}=\frac{G b}{\lambda}
$$

$T_{0}$ is the required compressive/tensile stress for forcing dislocations to move among reinforcement particles, $G$ is the elastic modulus of the matrix and reinforcement materials, and $b$ is the Burger's vector. Increasing the amount of $\mathrm{SiC}$ leads to a decrease of $\lambda$, resulting in a higher required compressive/tensile stress for the movement of dislocations between the $\mathrm{SiC}$ nanoparticles. The higher starting stress of dislocation motion eventually leads to the increase of the composite strength. 
Besides that, the increase in ultimate tensile strength can also be attributed to the mismatch at the interface of $\mathrm{Al}$ and $\mathrm{SiC}$ nanoparticles due to the large difference in the thermal expansion coefficient between matrix $\left(24 \times 10^{-6} / \mathrm{K}\right.$ for $\left.\mathrm{Al}\right)$ and reinforcement $\left(4.3 \times 10^{-6} / \mathrm{K}\right.$ for $\left.\mathrm{SiC}\right)$ [20]. The mismatch at the interface leads to the increase of dislocation density, which can be quantified by Equation (5):

$$
\rho=\frac{A \Delta \alpha \Delta T f}{b d(1-f)}
$$

where $A$ is a constant between 10 and 12 depending on the particle geometries, $\Delta \alpha$ is the difference of thermal expansion coefficient, $\Delta T$ is the difference between processing and test temperature, $d$ is the particle diameter, and $f$ is the volume fraction of nanoparticles [23]. The increase of dislocation density caused by the mismatch of coefficients of thermal expansion leads to the enhanced strength of the nanocomposites. This part of the strength contribution is named as $\Delta \sigma_{\mathrm{CTE}}$, which can be quantified by Equation (6):

$$
\Delta \sigma_{\mathrm{CTE}}=M \beta G b \sqrt{\rho},
$$

where $M$ is the Taylor factor, $\beta$ is a constant equal to $1.25, \rho$ is the density of dislocation mentioned in Equation (5), $G$ is the shear modules of the matrix, and $b$ the magnitude of Burger's vector [24,25]. We can infer from Equations (5) and (6) that with the volume fraction of nanoparticles $(v)$ increasing or the particle diameter $(d)$ decreasing, the total dislocation density in the nanocomposites increases, leading to a higher mismatch-reinforced strength $\left(\Delta \sigma_{\mathrm{CTE}}\right)$, which eventually adds to the yield strength of Al-SiC nanocomposites.

Fine-grain strengthening was also observed from the EBSD analyses. The inverse pole figures with the grain boundary of the blank sample and composites are demonstrated in Figure 9. In addition, the grain size distributions in the samples are depicted in Figure 10. The results revealed that the addition of nanoparticles led to grain refinement of the aluminium. The grain sizes of the specimen without $\mathrm{SiC}$ sample are distributed between 1 and $10 \mu \mathrm{m}$ with an average of $3.7 \mu \mathrm{m}$ (Figure 10a). However, in the case of the sample with the addition of $1 \mathrm{wt} \%, 2 \mathrm{wt} \%, 3 \mathrm{wt} \% \mathrm{SiC}$ nanoparticles, the grain sizes are distributed between 1 and $10 \mu \mathrm{m}$ with an average amount of $3.1 \mu \mathrm{m}, 2.6 \mu \mathrm{m}, 2.5 \mu \mathrm{m}$, respectively. As known from the Hall-Petch relationship:

$$
\sigma_{\text {Hall-Petch }}=K d^{-1 / 2} \text {. }
$$

The decrease of grain size will contribute to the enhancement of yield strength. Therefore, fine-grain strengthening is also accounting for the increased strength of the composites.

Table 2 lists the data used for calculating the strengthening effects of the composites. The calculated contribution of each strengthening mechanism is shown in Figure 11. The discrepancy is due to the assumptions made in the formulation of the equation and the interface defects as well as some

\begin{tabular}{|c|c|c|c|c|c|c|c|c|c|}
\hline$G$ & $b$ & $d$ & $\alpha_{\mathrm{Al}}$ & $\alpha_{\mathrm{SiC}}$ & $T_{\text {process }}$ & $T_{\text {test }}$ & \multicolumn{3}{|c|}{$K$} \\
\hline $\mathrm{GPa}$ & $\mathrm{nm}$ & $\mathrm{nm}$ & $\left(K^{-1}\right)$ & $\left(K^{-1}\right)$ & K & $\mathrm{K}$ & \multicolumn{3}{|c|}{$\mathrm{MPa} \cdot \mathrm{m}^{1 / 2}$} \\
\hline 26.4 & 0.286 & 50 & $24 \times 10^{-6}$ & $4.3 \times 10^{-6}$ & 773 & 298 & \multicolumn{3}{|c|}{0.0725} \\
\hline & & $\underset{\mu \mathrm{m}}{d_{\text {grain }}}$ & & & $\begin{array}{c}f \\
\text { vol \% }\end{array}$ & & $M$ & A & $\beta$ \\
\hline 0 & 1 wt $\%$ & 2 wt $\%$ & $3 w t \%$ & $1 \mathrm{wt} \%$ & $2 \mathrm{wt} \%$ & 3 wt $\%$ & - & - & - \\
\hline 3.7 & 3.1 & 2.6 & 2.5 & 0.85 & 1.7 & 2.54 & 3.1 & 12 & 1.25 \\
\hline
\end{tabular}
agglomeration of nanoparticles.

Table 2. Parameters for calculating the contribution of different strengthening mechanisms. 


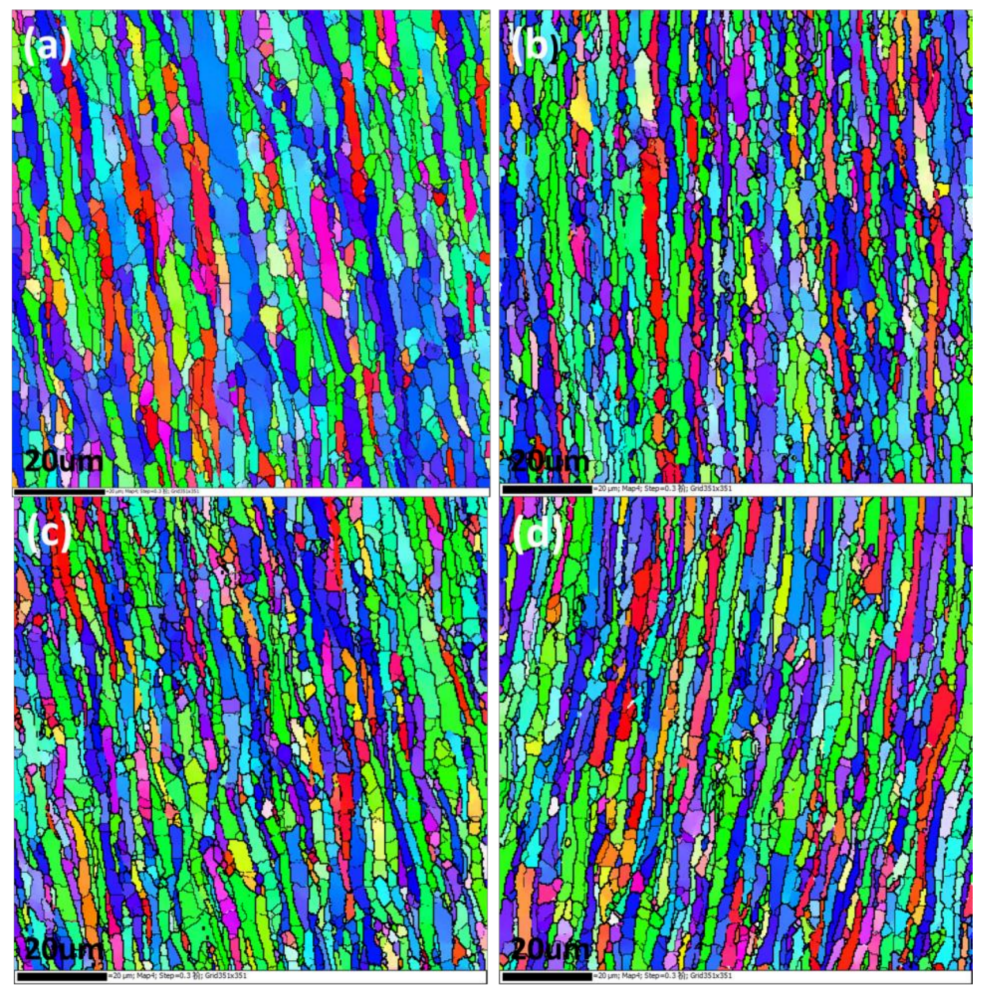

Figure 9. The inverse pole figure (IPF) map with grain boundaries for composites (a) pure aluminium; (b) Al-1 wt \% SiC; (c) Al-2 wt \% SiC; (d) Al-3 wt \% SiC.

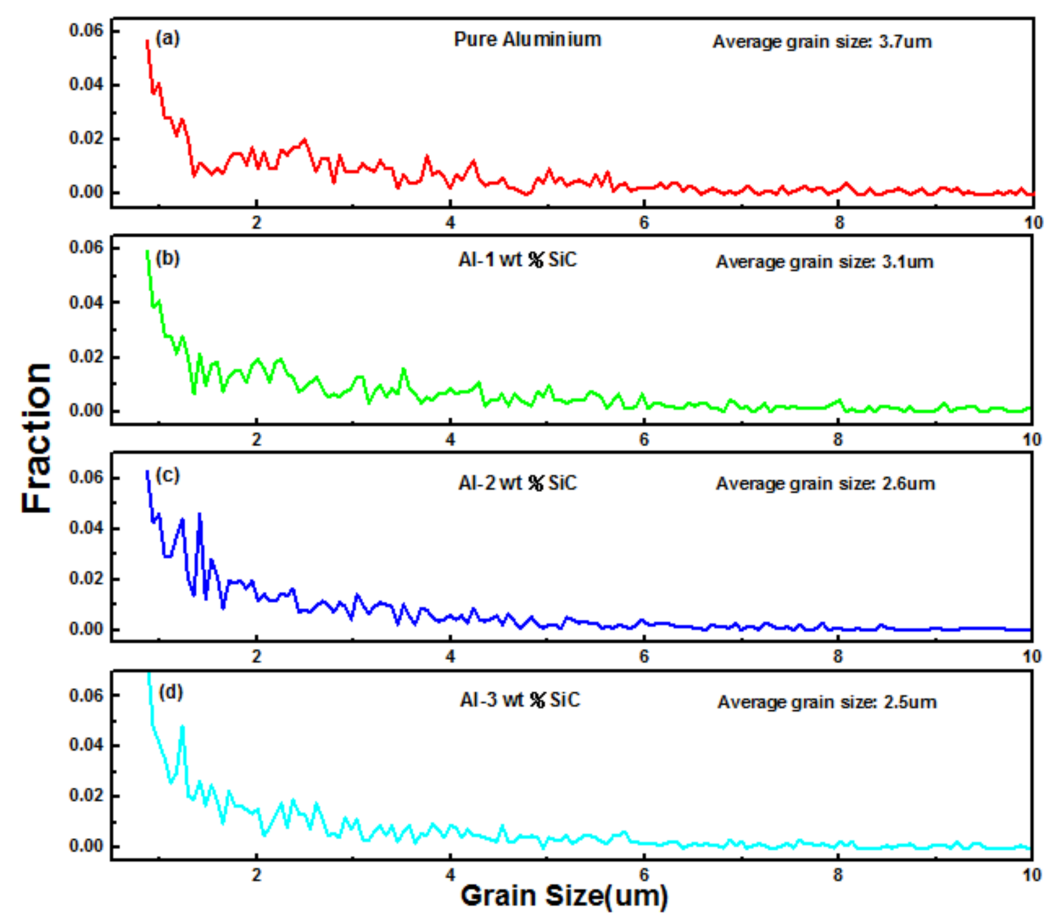

Figure 10. The grain-size distribution of composites (a) pure aluminium; (b) Al-1 wt \% SiC; (c) Al-2 wt \% $\mathrm{SiC} ;$ (d) Al-3 wt \% SiC.

However, the addition of $\mathrm{SiC}$ nanoparticles improves the ultimate tensile strength of aluminium while deteriorating the elongation. As seen from Figure 8, the elongation drops from $13.5 \%$ to $4.7 \%$ when adding $3 \mathrm{wt} \% \mathrm{SiC}$ nanoparticles to pure aluminium. In addition, the ultimate tensile strength of 
the composites undergoes no evident improvement while the content of SiC increases from 2-3 wt \%. These results may derive from the fact that the porosities of the composites increase with the addition of ceramic nanoparticles, which can be figured out from Figure 6. According to Rice-Tracey ductile criterion [26], the pores in the matrix tend to be the origin of cracks when tensile stress is acting on the composites, leading to a poor elongation of the composites.

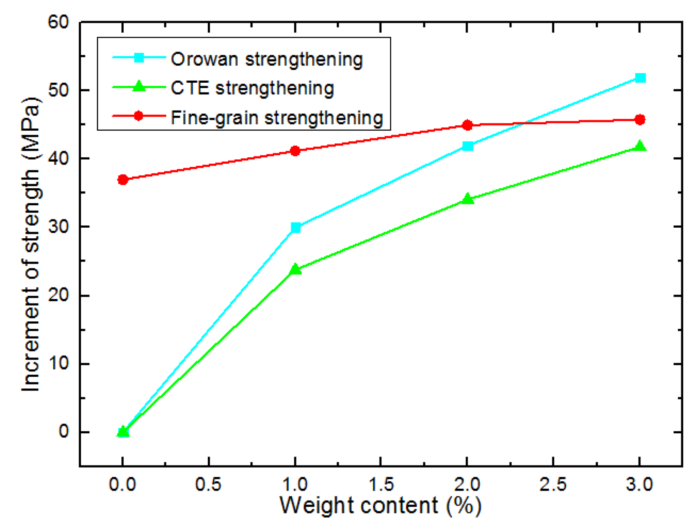

Figure 11. Calculated contribution of each strengthening mechanism.

\section{Conclusions}

In this work, a new method for the mixing process of metal matrix nanocomposites made by powder metallurgy was proposed. The mechanical properties and the microstructures of nanocomposites as-prepared were investigated. The important results and conclusions are summarized as follows:

1. Al-SiC nanocomposite was successfully synthesized by surface modified aluminium powder. The nanoparticles were distributed uniformly in the matrix alloy.

2. With the addition of $1,2,3 \mathrm{wt} \% \mathrm{SiC}$ nanoparticle to the aluminum matrix, the average hardness and tensile strength of the nanocomposite increased by about $26.0 \%, 34.5 \%, 40.0 \%$ and $22.3 \%$, $28.6 \%, 29.3 \%$, respectively.

3. A decrease in the ductility of the nanocomposite was found with the addition of nanoparticles. By adding $3 \mathrm{wt} \% \mathrm{SiC}$ nanoparticle, the elongation was decreased by $8.8 \%$ compared to the pure matrix metal.

Acknowledgments: This work was supported by the Shenzhen Engineering Laboratory of Nuclear Materials and Service Safety.

Author Contributions: Xiang Zeng and Qiulin Li conceived and designed the experiments. Xiang Zeng performed the experiments and wrote the paper. Wei Liu and Ben Xu analyzed the data. Guogang Shu contributed materials and analysis tools. All authors contributed to the discussions as well as revisions.

Conflicts of Interest: The authors declare no conflict of interest.

\section{References}

1. Zhang, L.J.; Yang, D.L.; Qiu, F.; Wang, J.G.; Jiang, Q.C. Effects of reinforcement surface modification on the microstructures and tensile properties of SiCp/Al2014 composites. Mater. Sci. Eng. A 2015, 624, 102-109. [CrossRef]

2. Mousavian, R.T.; Khosroshahi, R.A.; Yazdani, S.; Brabazon, D.; Boostani, A.F. Fabrication of aluminum matrix composites reinforced with nano- to micrometer-sized SiC particles. Mater. Des. 2016, 89, 58-70. [CrossRef]

3. Jiang, J.F.; Wang, Y. Microstructure and mechanical properties of the rheoformed cylindrical part of 7075 aluminum matrix composite reinforced with nano-sized SiC particles. Mater. Des. 2015, 79, 32-41. [CrossRef]

4. Zhang, L.J.; Qiu, F.; Wang, J.G.; Wang, H.Y.; Jiang, Q.C. Microstructures and mechanical properties of the Al2014 composites. Mater. Sci. Eng. A 2015, 637, 70-74. [CrossRef] 
5. Su, H.; Gao, W.L.; Feng, Z.H.; Lu, Z. Processing, microstructure and tensile properties of nano-sized $\mathrm{Al}_{2} \mathrm{O}_{3}$ particle reinforced aluminum matrix composites. Mater. Des. 2015, 36, 590-596. [CrossRef]

6. Zhou, D.S.; Qiu, F.; Jiang, Q.C. Simultaneously increasing the strength and ductility of nano-sized TiN particle reinforced Al-Cu matrix composites. Mater. Sci. Eng. A 2014, 596, 98-102. [CrossRef]

7. Yang, Y.; Lan, J.; Li, X.C. Study on bulk aluminum matrix nanocomposite fabricated by ultrasonic dispersion of nano-sized SiC particles in molten aluminum alloy. Mater. Sci. Eng. A 2004, 380, 378-383. [CrossRef]

8. Mazahery, A.; Shabani, M.O. Characterization of cast A356 alloy reinforced with nano SiC composites. Trans. Nonferr. Metals Soc. China 2012, 22, 275-280. [CrossRef]

9. Ma, Z.Y.; Tjong, S.C.; Li, Y.L.; Liang, Y. High temperature creep behaxior of nanometric $\mathrm{Si}_{3} \mathrm{~N}_{4}$ particulate reinforced aluminium composite. Mater. Sci. Eng. A 1997, 225, 125-134. [CrossRef]

10. Prasad Reddy, A.; Vamsi Krishna, P.; Narasimha Rao, R.; Murthy, N.V. Silicon carbide reinforced aluminium metal matrix nano composites-A review. Mater. Today Proc. 2017, 4, 3959-3971. [CrossRef]

11. Reyes, M.; Canul, M.; Torres, J. Development of aluminum hydroxides in Al-Mg-Si/SiCp in infiltrated composites exposed to moist air. Ceram. Int. 2011, 37, 2719-2722. [CrossRef]

12. Li, G.; Zhao, Y.; Wang, H.; Chen, G.; Dai, Q.; Cheng, X. Fabrication and properties of in situ $\left(\mathrm{Al}_{3} \mathrm{Zr}+\right.$ $\left.\mathrm{Al}_{2} \mathrm{O}_{3}\right) \mathrm{p} / \mathrm{A} 356$ composites cast by permanent mould and squeeze casting. J. Alloys Compd. 2009, 471, 530-535. [CrossRef]

13. Safari, J.; Chermahini, M.; Akbari, G. The effect of Mg content on microstructure and mechanical properties of $\mathrm{Al}-\mathrm{xMg} / 5 \mathrm{Al}_{2} \mathrm{O}_{3}$ nanocomposite prepared by mechanical alloying. Powder Technol. 2013, 234, 7-12. [CrossRef]

14. Wang, H.; Jiang, Q.; Wang, Y.; Ma, B.; Zhao, F. Fabrication of $\mathrm{TiB}_{2}$ particulate reinforced magnesium matrix composites by powder metallurgy. Mater. Lett. 2004, 58, 3509-3513. [CrossRef]

15. Qu, H.; Zhu, S.; Li, Q. Influence of sintering temperature and holding time on the densification, phase transformation, microstructure and properties of hot pressing WC -40 vol. $\% \mathrm{Al}_{2} \mathrm{O}_{3}$ composites. Ceram. Int. 2012, 38, 1371-1380. [CrossRef]

16. Naher, S.; Brabazon, D.; Looney, L. Development and assessment of a new quick quench stir caster design for the production of metal matrix composites. J. Mater. Process. Technol. 2004, 166, 430-439. [CrossRef]

17. Cabeza, M.; Feijoo, I.; Merino, P.; Pena, G. Effect of high energy ball milling on the morphology, microstructure and properties of nano-sized TiC particle-reinforced 6005A aluminium alloy matrix composite. Powder Technol. 2017, 321, 31-43. [CrossRef]

18. Soltani, M.; Atrian, A. High temperature tensile behavior and microstructure of Al-SiC nanocomposite fabricated by mechanical milling and hot extrusion technique. Mater. Res. Express 2018, 5, 025026. [CrossRef]

19. Issa, H.; Taherizadeh, A.; Maleki, A. Development of an aluminium/amorphous nano-SiO ${ }_{2}$ composite using powder metallurgy and hot extrusion processes. Ceram. Int. 2017, 43, 14582-14592. [CrossRef]

20. Penchal, M.; Shakoora, R.A. Enhanced performance of nano-sized SiC reinforced Al metal matrix nanocomposites synthesized through microwave sintering and hot extrusion techniques. Prog. Nat. Sci. Mater. Int. 2017, 27, 606-614.

21. Dieter, G.E.; Bacon, D. Mechanical Metallurgy; McGraw-Hill: New York, NY, USA, 1986.

22. Ramezanalizadeh, H.; Emamy, M.; Shokouhimehr, M. A novel aluminum based nanocomposite with high strength and good ductility. J. Alloys Compd. 2015, 649, 461-473. [CrossRef]

23. Zadeh, S.A. Comparison between current models for the strength of particulate reinforced metal matrix nanocomposites with emphasis on consideration of Hall-Petch effect. Mater. Sci. Eng. A 2012, 531, 112-118. [CrossRef]

24. Hassan, S.F.; Tan, M.J.; Gupta, M. High-temperature tensile properties of $\mathrm{Mg} / \mathrm{Al}_{2} \mathrm{O}_{3}$ nanocomposite. Mater. Sci. Eng. A 2008, 486, 56-62. [CrossRef]

25. Tun, K.S.; Gupta, M. Effect of heating rate during hybrid microwave sintering on the tensile properties of magnesium and $\mathrm{Mg} / \mathrm{Y}_{2} \mathrm{O}_{3}$ nanocomposite. J. Alloys Compd. 2008, 466, 140-145. [CrossRef]

26. Rice, J.K.; Tracey, D.M. On the ductile enlargement of voids in triaxial stress fields. J. Mech. Phys. Solids 1967, 117, 201-217. [CrossRef]

(C) 2018 by the authors. Licensee MDPI, Basel, Switzerland. This article is an open access article distributed under the terms and conditions of the Creative Commons Attribution (CC BY) license (http:/ / creativecommons.org/licenses/by/4.0/). 